\title{
Optimal integration of capacitor and PV in distribution network based on nomadic people optimizer
}

\author{
Hussein Abdel-Mawgoud ${ }^{1}$, Salah Kamel' ${ }^{2}$, Sinan Q. Salih ${ }^{3}$, Ali S. Alghamdi \\ ${ }^{1,2}$ Department of Electrical Engineering, Faculty of Engineering, Aswan University, Aswan, Egypt \\ ${ }^{3}$ Computer Science Department, Dijlah University College, Baghdad, Iraq \\ ${ }^{4}$ Department of Electrical Engineering, College of Engineering, Majmaah University, Majmaah 11952, \\ Saudi Arabia
}

\begin{tabular}{l} 
Article Info \\
\hline Article history: \\
Received Dec 30 \\
Revised Jun 6, 2 \\
Accepted Jun 18, \\
\hline Keywords: \\
Capacitor \\
NPO algorithm \\
PV \\
RDS \\
Sensitivity
\end{tabular}

\section{Corresponding Author:}

Salah Kamel

Department of Electrical Engineering, Faculty of Engineering

Aswan University, 81542 Aswan, Egypt

Email: skamel@aswu.edu

\begin{abstract}
Since the last decades, capacitor and photovoltaics (PV) are installed in distribution networks to meet the increasing in system loads. In this paper, a new application of nomadic people optimizer (NPO) algorithm is proposed to obtain the best locations and sizes of capacitor and PV alone or simultaneously in radial distribution system (RDS). Also, reactive loss sensitivity factor (QLSF) can be used for obtaining the candidate locations for installing PV and capacitor units in RDS. The efficiency of the presented technique can be applied on IEEE 69-bus and IEEE 33-bus RDS. From simulation result, installing capacitor and PV units alone in RDS decreases the total losses and increases the bus voltages. Also, simultaneous integration of PV and capacitor units give better results than integration capacitor and PV units alone in distribution network. The presented algorithm is able to explore most area of search and obtain better results than recent optimizations algorithms.
\end{abstract}

This is an open access article under the CC BY-SA license.

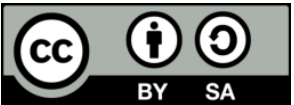

\section{INTRODUCTION}

In last decades, integration of natural sources in RDS is increasing to withstand the increasing in worldwide load demand [1]-[4]. There are different types of natural sources are utilized in power grid such as hydropower, biomass, photovoltaic (PV) and wind turbine [5]-[7]. Installing PV in RDS is increased rapidely as it generates electricity from solar energy in silent and clean way [1]-[4]. Installing of capacitor in RDS is becoming more popular to reduce the reactive power supplied from substation. Therefore, integrating capacitor and PV in RDS increases the system capacity, reduces the system power loss and enhances the system voltage. QLSF are used to determine the best fifty percent of system buses for integration capacitor and PV in distribution networks [8], [9]. The presented objective function is formulated by increasing the voltage stability index and decreasing the voltage deviation and system losses as multi-objective function.

NPO algorithm is a new metaheuristic optimization algorithm to simulate the human behavior in their motion when searching for water and food [10]. This algorithm consists of several clans (swarms) and each clan consists of several families around a single leader. This algorithm depends on multi-swarm method and each swarm search for the best solution that is represented by the leadr. Also, most metaheuristic optimization algorithms have faced a main problem of achieving a balance between exploration and exploitation phase, but NPO algorithm has solved this problem by its operators. These operators are families 
searching, semicircular distribution, initial meeting, periodical meeting and leadership transition. The metaheuristic algorithms that are applied to determine the best sizes and locations of PV and capacitor in distribution network are genetic algorithm (GA) [11], [12], moth-flame optimization (MFO) algorithm [13], whale optimization algorithm (WOA) [14], backtracking search optimization algorithm (BSOA) [15], firefly algorithm (FFA) [16], multileader particle swarm optimization (MLPSO) algorithm [17], lightning search algorithm (LSA) [18] and flower pollination algorithm (FPA) [19].

The contributions of the paper are; i) using an efficient recent algorithm to determine the optimal planning of PV and capacitor in RDS; ii) studying the effect of integrating PV and capacitor alone in RDS; iii) studying the effectof integrating PV with capacitor in RDS; and iv) NPO algorithm is compared with efficient algorithms to measure its performance in solving optimization problem. This paper can be divided into subsections as follows: the mathematical problem is formulated in section 2, the sensitivity is explained in section 3, section 4 explains the presented algorithm, and section 5 discusses the obtained results. Section 6 displays the conclusion of the paper.

\section{MATHEMATICAL PROBLEM}

Figure 1 displays the representation of two buses in distribution system.

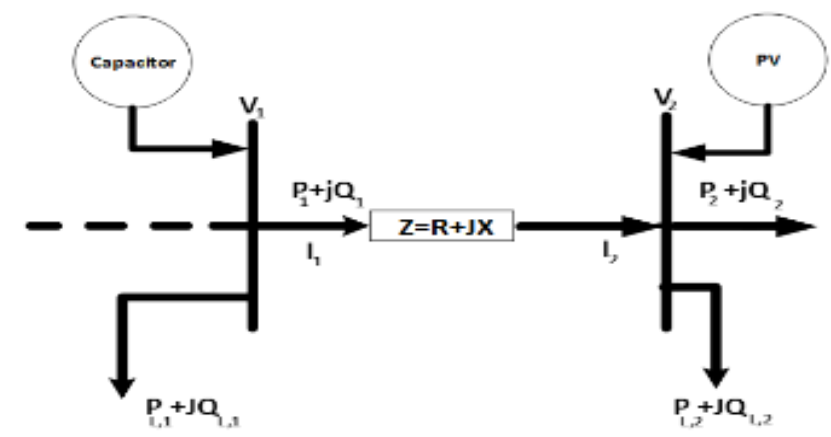

Figure 1. Representation of two buses in distribution system

In backward direction, the reactive and real power can be obtained as follows [20]:

$$
\begin{aligned}
& P_{1}=P_{2}+P_{L 2}+R\left(\frac{\left(P_{2}+P_{L 2}\right)^{2}+\left(Q_{2}+Q_{L 2}\right)^{2}}{\left|V_{2}\right|^{2}}\right) \\
& Q_{1}=Q_{2}+Q_{L 2}+X\left(\frac{\left(P_{2}+P_{L 2}\right)^{2}+\left(Q_{2}+Q_{L 2}\right)^{2}}{\left|V_{2}\right|^{2}}\right)
\end{aligned}
$$

Then, the voltage magnitude of bus (2) can be determined in forward direction as follow:

$$
V_{2}^{2}=V_{1}^{2}-2\left(P_{1} R+Q_{1} X\right)+\left(R^{2}+X^{2}\right) \frac{\left(P_{1}^{2}+Q_{1}{ }^{2}\right)}{V_{1}^{2}}
$$

The problem formulation can be presented as multi-objective function as follows:

$$
\begin{aligned}
& f_{t}=k_{1} f_{1}+k_{2} f_{2}+k_{3} f_{3} \\
& f_{1}=\sum_{m=1}^{B}\left(P_{\text {loss }}(m)\right) \\
& f_{2}=\sum_{m=1}^{S}(\operatorname{VD}(m)) \\
& f_{3}=\frac{1}{\sum_{m=1}^{S}(|\operatorname{VSI}(m)|)} \\
& \left|k_{1}\right|+\left|k_{2}\right|+\left|k_{3}\right|=1
\end{aligned}
$$

where, $V D(m)$ represents the voltage deviation at bus $(\mathrm{m}), \operatorname{VSI}(\mathrm{m})$ represents the voltage stability index at bus $(\mathrm{m}), \mathrm{B}$ and $\mathrm{S}$ are the total number of branches and buses. $k_{1}, k_{2}$ and $k_{3}$ are weighting factors that are equal to $0.5,0.25$ and 0.25 , respectively. 


\subsection{Voltage stability index}

Voltage stability index (VSI) is applied to measure the system security. Therefore, VSI can be used to measure the sensitivity of each bus to voltage collapse in RDS by (9) [21]. As long as the value of VSI for bus system is closer to $1 \mathrm{pu}$, the bus voltage is closer to steady state voltage limit. Also, when the value of VSI for bus system is closer to $0 \mathrm{pu}$, the bus voltage is far from steady state voltage limit Therefor, the bus is more stable when the VSI for this bus is high and the possibilities of voltage collapse at this bus is weak. Summation of voltage stability index is the summation of VSI for system buses.

$$
V S I_{(2)}=\left|V_{1}\right|^{4}-4\left(P_{2} X_{1,2}-Q_{2} R_{1,2}\right)^{2}-4\left(P_{2} X_{1,2}+Q_{2} R_{1,2}\right)\left|V_{1}\right|^{2}
$$

Where, $V S I_{(2)}$ represents the VSI for bus (2), $X_{1,2}$ and $R_{1,2}$ represent the reactance and the resistance among buses (1) and (2). $V_{1}$ represents the voltage at bus (1). But, $Q_{2}$ and $P_{2}$ represent the reactive and real power injection from bus (2) to RDS.

\subsection{Voltage deviation}

The power equality and security index can be measured using bus voltage. Therefore, any change in bus voltage affects the operation of power grid that is calculated by the voltage deviation (VD).

$$
V D=\left(V_{u}-V_{\text {ref }}\right)^{2}
$$

Where, $V_{\text {ref }}$ represents the value that is equal to $1 \mathrm{pu}$. The optimal locations and sizes of capacitor and PV can be calculated under equality and inequality constraints as shown next.

\subsubsection{Equality contraints}

Theses constraints includes power flow balance equation that can be represented as follows:

$$
\begin{aligned}
& P_{S}+\sum_{m=1}^{M} P_{P V}(m)=\sum_{m=1}^{S} P_{L, m}+\sum_{m=1}^{B} P_{\text {loss }}(m) \\
& Q_{S}+\sum_{m=1}^{N} Q_{\text {Capacitor }}(m)=\sum_{m=1}^{S} Q_{L, m}+\sum_{m=1}^{B} Q_{\text {loss }}(m) \\
& P_{1}=P_{2}+P_{L 2}+R\left(\frac{\left(P_{2}+P_{L 2}\right)^{2}+\left(Q_{2}+Q_{L 2}\right)^{2}}{\left|V_{2}\right|^{2}}\right) \\
& Q_{1}=Q_{2}+Q_{L 2}+X\left(\frac{\left(P_{2}+P_{L 2}\right)^{2}+\left(Q_{2}+Q_{L 2}\right)^{2}}{\left|V_{2}\right|^{2}}\right)
\end{aligned}
$$

where, $P_{L, m}$ and $P_{S}$ are the active load demand and active power injection from substation, respectively. $Q_{L, m}$ and $Q_{S}$ are reactive load demand and reactive power injection from substation, respectively. $M$ and $N$ are the total number of PV and capacitor in RDS, respectively. $P_{P V}(m)$ and $Q_{\text {Capacitor }}(m)$ are output power of PV and capacitor at bus $(m)$, respectively.

\subsubsection{Inequality constraints}

Theses constraints are formulated as follows:

- System voltage constraints

The bus system voltage is operating within the minimum operating voltage $\left(V_{\text {down }}\right)$ and the maximum operating voltage $\left(V_{u p}\right)$.

$$
V_{\text {down }} \leq V_{c} \leq V_{u p}
$$

- $\quad$ DER sizing limits

$$
\begin{aligned}
& \sum_{c=1}^{M} P_{P V}(c) \leq\left(\sum_{c=1}^{S} P_{L, c}+\sum_{c=1}^{B} P_{\text {loss }}(c)\right) \\
& P_{P V, n} \leq P_{P V} \leq P_{P V, a}
\end{aligned}
$$

PV output operates within the minimum $\left(P_{P V, n}\right)$ and maximum power $P_{P V, a}$ of PV in RDS.

- Capacitor sizing limits

$$
\sum_{c=1}^{N} Q_{\text {Capacitor }}(c) \leq\left(\sum_{c=1}^{S} Q_{L, m}+\sum_{c=1}^{B} Q_{\text {loss }}(c)\right)
$$




$$
Q_{\text {Capacitor }, n} \leq Q_{\text {Capacitor }} \leq Q_{\text {Capacitor, } a}
$$

The output power of capacitor is operating within the minimum $\left(Q_{\text {Capacitor }, n}\right)$ and maximum power $Q_{\text {Capacitor, } a}$ of PV in RDS.

- Line capacity limits

The branches current of the system is operating under operating constraints.

$$
I_{m} \leq I_{a, m} \quad k=1,2,3, \ldots, N . b
$$

Where, $I_{a, m}$ is the maximum operating current through the branch $(m)$.

\subsection{Reactive loss sensitivity factor (QLSF)}

QLSF measure the change in active power loss by injecting reactive power in system buses as shown in (21).

$$
Q L S F=\frac{\partial P_{\operatorname{loss}(m, m+1)}}{\partial Q_{m+1}}=R_{m, m+1}\left(\frac{2 Q_{m+1}}{\left|V_{m+1}\right|^{2}}\right)
$$

Figure 2 and Figure 3 shows the QLSF for the presented systems, respectively. The buses with maximum QLSF values up to $50 \%$ of system buses can be defined as a candidate bus for PV and capacitor installation in RDS. The obtained candidate buses for IEEE 33-bus RDS are 6, 3, 28, 8, 29, 4, 5, 30, 9, 24, 13, 10, 27, 31, 2, 26 and 23. Also, the obtained candidate buses for IEEE 69-bus RDS are 57, 58, 7, 6, 61, 60, 10, $59,55,56,12,54,13,14,15,53,8,64,49,11,9,17,48,65,5,16,21,19,41,63,68,34,20,62$ and 33.

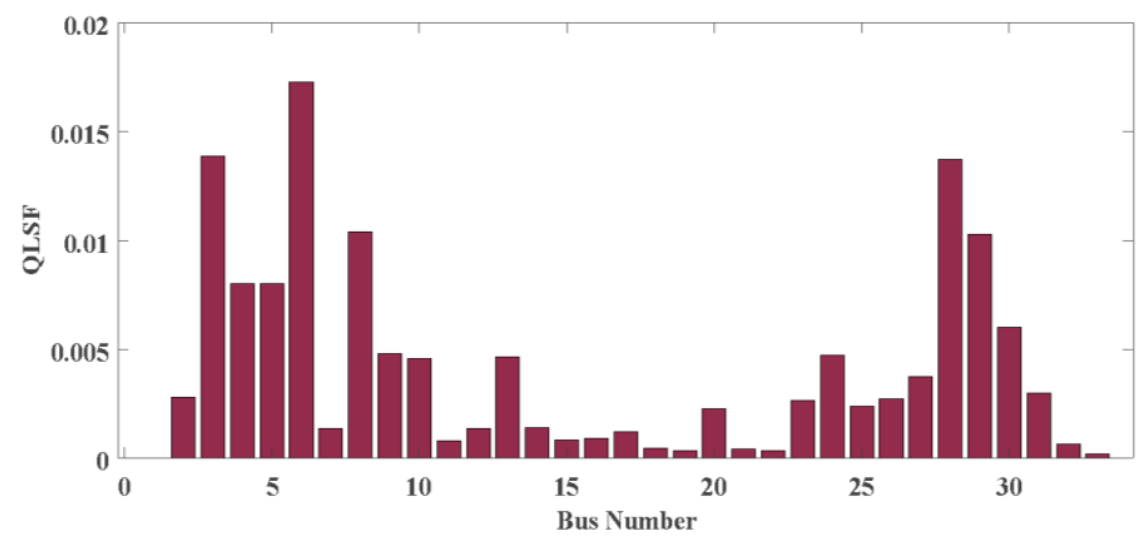

Figure 2. QLSF for IEEE 33-bus RDS

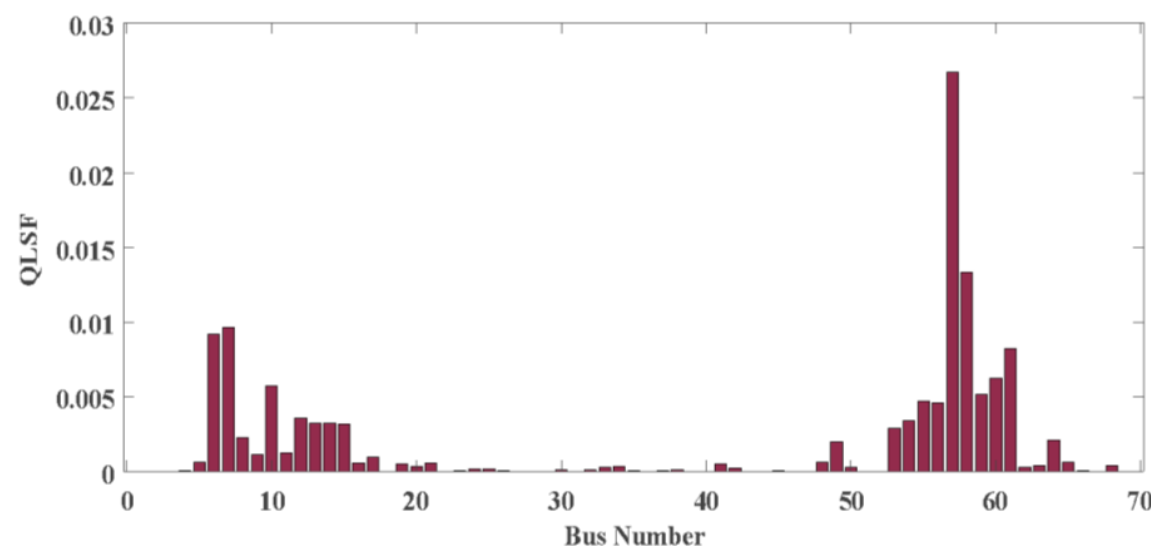

Figure 3. QLSF for IEEE 69-bus RDS 


\subsection{Nomadic people optimized algorithm}

NPO is a recent metaheuristic algorithm that is inspired from human behavior in their motion when searching for water and food [10]. The main operators of NPO algorithm are families searching, semicircular distribution, initial meeting, periodical meeting and leadership transition. The steps of NPO algorithm to determine the optimal sizes and locations of PV and capacitor in distribution networks can be summarized as shown next.

Step 1: Enter system data, number of leaders $(\sigma)$, number of families $(X)$ and maximum iteration

Step 2: Generate initial population of leaders (clans) through initial meeting operator by (22):

$$
\sigma_{i}=l b+\operatorname{rand}(u b-l b)
$$

where, $l b$ and $u b$ are the lower and upper value of control variables. rand is a random value between (0) and (1).

Step 3: Set the position of families $X_{i, j}$ around each leader through semicircular distribution operator by (23):

$$
X_{i, j}=\sigma_{i} \times \sqrt{R} \times|\cos \cos (\theta) \quad|
$$

where, $X_{i, j}$ is the position of family $(j)$ at clan $(i)$ around a leader $\sigma_{i} . \mathrm{R}$ is a random value between $(0)$ and (1) and $\theta$ is the angle between the point of family position and the point of leader position which lies between $(0,2 \pi)$.

Step 4: Evaluate the fitness function for all locations of family in all swarms and obtain the best position of family $X_{i, j}^{B}$ in all clans or swarms.

Step 5: Set the original leader $\sigma_{i}$ equal to $X_{i, j}^{B}$ as long as $X_{i, j}^{B}$ is better than $\sigma_{-} \mathrm{i}$ in all clans. If $\sigma_{i}$ is better than $X_{i, j}^{B}$, the families searching operator will do the next steps.

- Evaluate the average distance among all families by (24)

$$
d \frac{\sum_{i=1}^{E} \sqrt{\left(\sigma_{i}-X_{i, j}\right)^{2}}}{E}
$$

where, E represents the total number of families in each clan.

- Move the position of family to a new position by (25):

$$
X_{\text {new } i, j}=X_{i, j}+\left(d \times\left(\sigma_{i}-X_{i, j}\right) \oplus L e v y\right)
$$

Step 6: Evaluate the fitness function for all locations of new position of families in all swarms.

Step 7: Set the position of leader $\sigma_{i}$ equal to $X_{\text {new } i, j}^{B}$ as long as $X_{n e w ~}^{B}, j$ is better than $\sigma_{i}$ in all clans.

Step 8: Update the position of leaders in all clans through the periodical meeting operator by (26)

$$
\begin{aligned}
& \sigma_{\text {new } i}=\sigma_{i}+\Delta P O S\left(\left(\sigma_{i}^{B}-\sigma_{i}\right) \times \frac{t}{T}\right) \\
& \triangle P O S=\varphi\left(\frac{\sqrt{\sum_{i=1}^{D}\left(\sigma_{i}^{B}-\sigma_{i}\right)^{2}}}{D}\right)
\end{aligned}
$$

where, $\triangle \mathrm{POS}$ is the distance among the normal leader and best leader, $\varphi$ refers to the direction and $D$ is the number of dimensions for the presented optimization problem.

Step 9: Back to step 3 until the final iteration is reached.

Step 10: Obtain the best leader $\left(\sigma_{i}^{B}\right)$ in all clans (positions and sizes of PV and capacitor).

\section{SIMULATION RESULTS}

IEEE 33-bus RDS has thirty-three buses with reactive load of 2.3 MVAR and active load of 3.715 MW and IEEE 69-bus RDS consists of sixty-nine buses with reactive load of 2694.6 KVAR and active load of $3801.5 \mathrm{KW}$ as shown in Figure 4 and Figure 5 [22], [23]. The base values for these systems are 10 MVA and $12.66 \mathrm{KV}$ base values. The used system constraints and algorithm parameters is introduced in Table 1. 


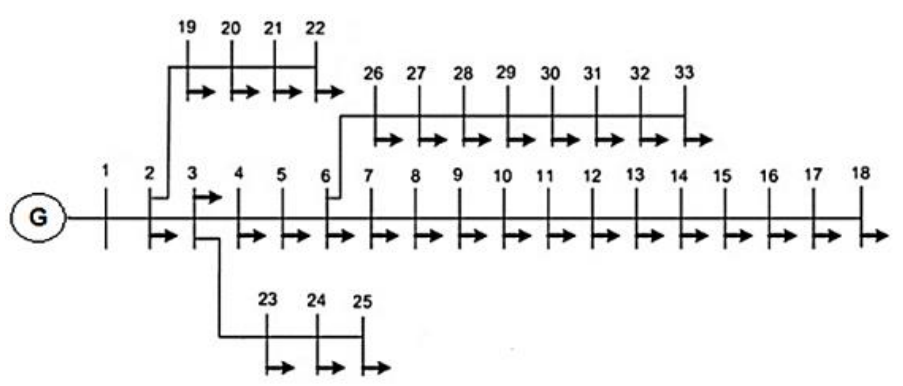

Figure 4. IEEE 33-bus RDS

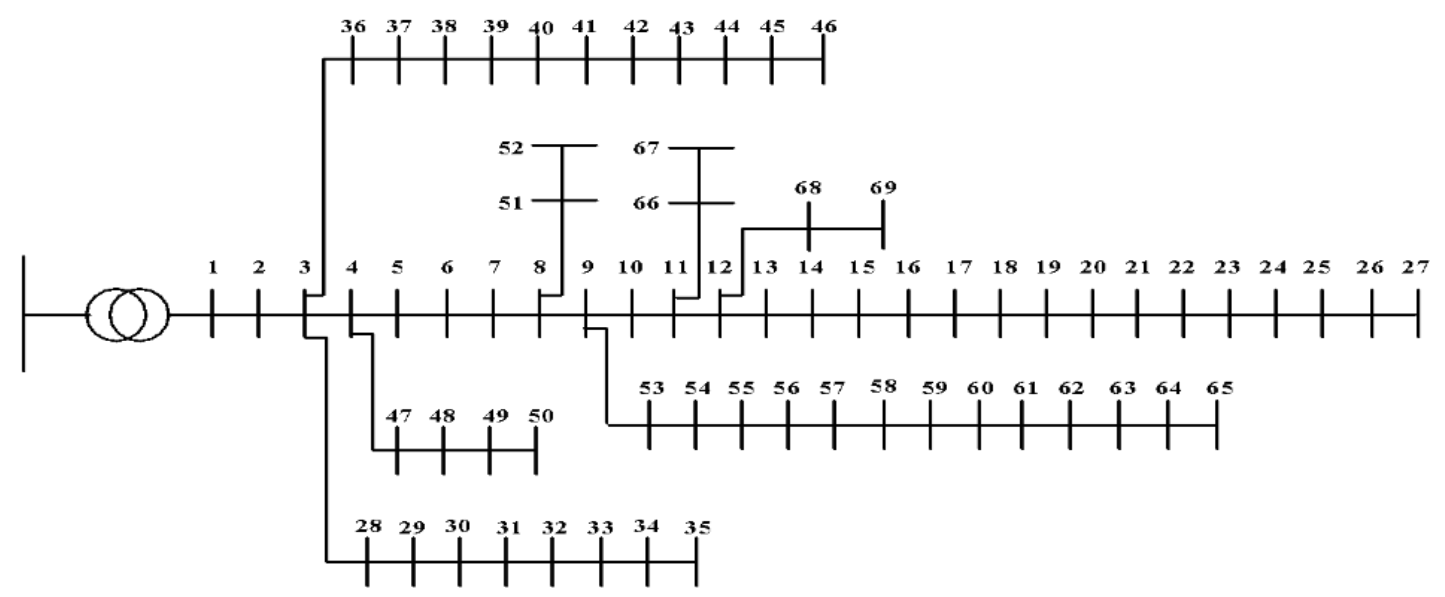

Figure 5. IEEE 69-bus RDS

Table 1. The used parameters

\begin{tabular}{lc}
\hline \multicolumn{1}{c}{ The used parameters } & The proposed value \\
\hline Number of leaders & 5 \\
Number of families & 500 \\
Maximum iteration & 100 \\
Voltage limits & $0.9 \mathrm{pu} \leq V_{i} \leq 1.05 \mathrm{pu}$ \\
Limits of active output generation from DG & $0.3 \mathrm{MW} \leq P_{D G, i} \leq 3 \mathrm{MW}$ \\
Limits of reactive power generation from capacitor & $50 \mathrm{KVAR} \leq P_{D G, i} \leq 1500 \mathrm{KVAR}$ \\
\hline
\end{tabular}

\subsection{IEEE 33-bus RDS}

Without integration PV and capacitor units in RDS, the system loss and the summation of the voltage deviation of the system are $210.972 \mathrm{KW}, 0.1338 \mathrm{pu}$, respectively. Also, the summation of voltage stability index of the system is 25.539 with minimum voltage of 0.9038 pu at bus 18 . Integration of one, two and three of PV alone in distribution network decreases the system losses to $111.02 \mathrm{KW}, 87.165 \mathrm{KW}$ and $72.785 \mathrm{KW}$, respectively as shown in Table 2. Integration one and two PV alone in RDS enhance the summation of voltage stability index to 28.522 and 29.3867 and reduce the voltage deviation to $0.03771 \mathrm{pu}$ and $0.0169 \mathrm{pu}$, respectively. Integration of three PV alone in RDS decreases the summation of voltage deviation to $0.0151 \mathrm{pu}$, improves the summation of voltage stability index to 29.617 and enhances the minimum voltage to $0.9687 \mathrm{pu}$ at bus 33. Also, integration of one, two and three capacitors alone in distribution network decreases the system losses to $151.359 \mathrm{KW}, 141.826 \mathrm{KW}$ and $138.873 \mathrm{KW}$, respectively as shown in Figure 6. The summation of voltage stability index is improved to 26.799, 27.322 and 27.244 and summation of voltage deviation is reduced to $0.0838 \mathrm{pu}, 0.0635 \mathrm{pu}$ and $0.0664 \mathrm{pu}$ by integrating one, two and three capacitors alone in RDS, respectively. Also, the minimum voltage is enhanced to $0.9165 \mathrm{pu}$, 0.9304 pu and 0.9298 pu at bus 18 by installing one, two and three capacitors alone in RDS.

From Table 2, incorporating PV with capacitor units simultaneously obtains superior results than incorporating PV alone or capacitor alone in RDS. Therefore, simultaneous integration of one, two and three PV with capacitor units in RDS reduces the system power loss to $58.443 \mathrm{KW}, 28.578 \mathrm{KW}$ and $11.740 \mathrm{KW}$, respectively. From Figure 7, the minimum bus voltage is enhanced to 0.9537 pu at bus 18, 0.9804 pu at bus 25 and 0.9921 pu at bus 8 by integrating one, two and three PV with capacitor units simultaneously in RDS, 
respectively. From Figure 8, integration of one and two PV with capacitor units simultaneously in RDS improves the summation of voltage stability index to 29.805 and 31.2678 , respectively. Installing three PV with capacitor units simultaneously in RDS achieves the best results as it reduces the summation of voltage deviation to $0.0006 \mathrm{pu}$ and enhances the summation of voltage stability index to 31.5127. The summation of voltage deviation of the system is reduced to $0.0173 \mathrm{pu}$ and $0.0016 \mathrm{pu}$ by integrating one and two PV with capacitor simultaneously in RDS, respectively. From Table 3, NPO algorithm is an efficient to obtain the best results in minimizing the system losses to $111.17 \mathrm{KW}$ compared to WOA with system losses $133.503 \mathrm{KW}$ for integrating one PV alone in RDS.

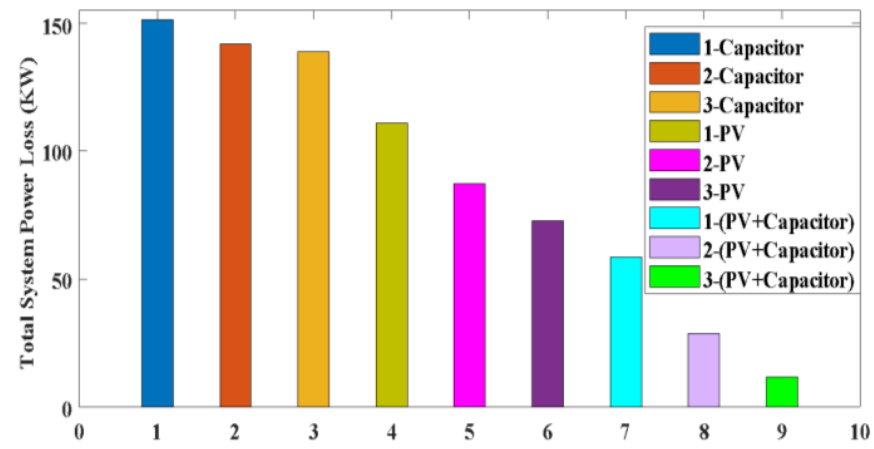

Figure 6. System losses by integrating capacitor and PV units alone or simultaneously in IEEE 33-bus RDS

Table 2. The obtained results for integrating PV alone, capacitor alone, and PV with capacitor simultaneously

\begin{tabular}{|c|c|c|c|c|c|c|}
\hline Item & $\begin{array}{c}\text { Bus (PV size } \\
(\mathrm{KW}))\end{array}$ & $\begin{array}{c}\text { Bus (capacitor size } \\
(\mathrm{KW}))\end{array}$ & $\begin{array}{c}P_{\text {loss }} \\
(\mathrm{KW})\end{array}$ & VD & VSI & $\begin{array}{l}\text { Bus (minimum } \\
\text { voltage }(\mathrm{pu}))\end{array}$ \\
\hline $\begin{array}{l}\text { Without PV and } \\
\text { Capacitor }\end{array}$ & - & - & 210.972 & 0.133797 & 25.539 & $18(0.9038)$ \\
\hline 1-PV alone & $6(2590.65)$ & - & 111.016 & 0.03771 & 28.522 & $18(0.9424)$ \\
\hline 2-PV alone & $\begin{array}{l}13(851.83) \\
30(1157.7)\end{array}$ & - & 87.165 & 0.0169 & 29.3867 & $33(0.9685)$ \\
\hline 3-PV alone & $\begin{array}{c}13(802.302) \\
30(1053.2) \\
24(1091.2)\end{array}$ & - & 72.785 & 0.0151 & 29.617 & $33(0.9687)$ \\
\hline 1-Capacitor alone & - & $30(1258)$ & 151.359 & 0.0838 & 26.799 & $18(0.9165)$ \\
\hline 2-Capacitor alone & - & $\begin{array}{c}30(1063) \\
12(466)\end{array}$ & 141.826 & 0.0635 & 27.322 & $18(0.9304)$ \\
\hline 3-Capacitor alone & - & $\begin{array}{l}13(359) \\
30(999) \\
24(367)\end{array}$ & 138.873 & 0.0664 & 27.244 & $18(0.9298)$ \\
\hline 1-(PV+Capacitor) & 6(2531.99) & $30(1256)$ & 58.443 & 0.0173 & 29.805 & $18(0.9537)$ \\
\hline 2-(PV+Capacitor) & $\begin{array}{c}30(1139.596) \\
13(846.235)\end{array}$ & $\begin{array}{l}30(1032) \\
10(468)\end{array}$ & 28.578 & 0.0016 & 31.2678 & $25(0.9804)$ \\
\hline 3-(PV+Capacitor) & $\begin{array}{c}30(1029.75) \\
24(1070) \\
13(793.98)\end{array}$ & $\begin{array}{c}30(1012) \\
24(517) \\
13(373) \\
\end{array}$ & 11.740 & 0.0006 & 31.5127 & $8(0.9921)$ \\
\hline
\end{tabular}

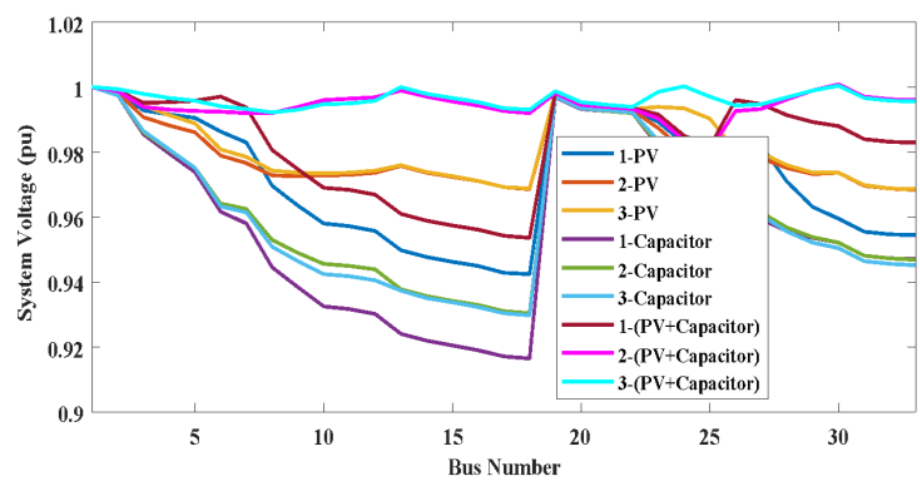

Figure 7. Bus voltages by integrating PV and capacitor units alone or simultaneously in IEEE 33-bus RDS 


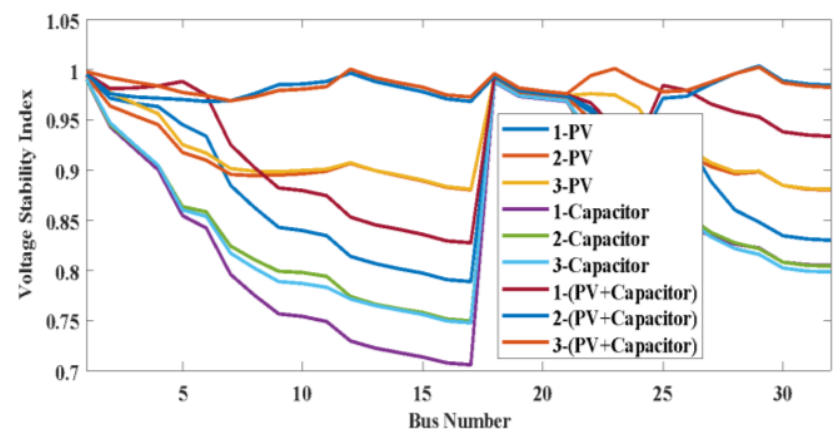

Figure 8 . Voltage stability index of the system by integrating PV and capacitor units alone or simultaneously in IEEE 33-bus RDS

Table 3. The comparison results between the presented algorithm and other algorithms in IEEE 33-bus RDS

\begin{tabular}{lccccc}
\hline \multicolumn{1}{c}{ Item } & NPO & Hybrid [24] & WOA [25] & SCA [26] & PSO [27] \\
\hline 1-PV alone & 111.016 & 111.17 & 125.161 & - & - \\
2-PV alone & 87.165 & 87.28 & - & - & - \\
3-PV alone & 72.785 & 72.89 & - & - & - \\
1-Capacitor alone & 151.359 & - & 151.379 & - & - \\
2-Capacitor alone & 141.826 & - & - & 142.551 & - \\
3-Capacitor alone & 138.873 & - & - & - & - \\
1-(PV+Capacitor) & 58.443 & - & - & - & 59.7 \\
2-(PV+Capacitor) & 28.578 & - & - & - & - \\
3-(PV+Capacitor) & 11.740 & - & - & - & - \\
\hline
\end{tabular}

\subsection{IEEE 69-bus RDS}

Without integration PV and capacitor units in RDS, the power loss is $224.975 \mathrm{KW}$ with minimum voltage of $0.9092 \mathrm{pu}$ at bus 65 . Also, the summation of voltage deviation and voltage stability index of the system are 0.0994 pu and 61.218, respectively. From Figure 9, the system losses are reduced to 83.2224 KW, $71.6745 \mathrm{KW}$ and $69.4266 \mathrm{KW}$ by integrating one, two and three PV alone in RDS, respectively. The summation of voltage stability index is enhanced to 61.2184 and 64.6214 and the summation of voltage deviation is decreased to $0.0994 \mathrm{pu}$ and $0.0201 \mathrm{pu}$ by integrating one and two PV alone in RDS, respectively. The summation of voltage deviation is decreased to $0.0061 \mathrm{pu}$, the summation of voltage stability index is improved to 66.226 and the minimum voltage is improved to $0.9789 \mathrm{pu}$ at bus 65 by integrating three PV alone in RDS. From Table 4, integration of one, two and three capacitors alone in distribution network decreases the system losses to $152.041 \mathrm{KW}, 146.441 \mathrm{KW}$ and $145.129 \mathrm{KW}$, respectively. Installing one, two and three capacitors alone in RDS improve the minimum voltage to $0.9307 \mathrm{pu}, 0.9311 \mathrm{pu}$ and $0.9314 \mathrm{pu}$ at bus 65 as shown in Figure 10. The summation of voltage stability index is improved to 62.3427, 62.7094 and 62.8044 and summation of voltage deviation is reduced to $0.0641 \mathrm{pu}, 0.0574 \mathrm{pu}$ and $0.0559 \mathrm{pu}$ by integrating one, two and three capacitors alone in RDS, respectively.

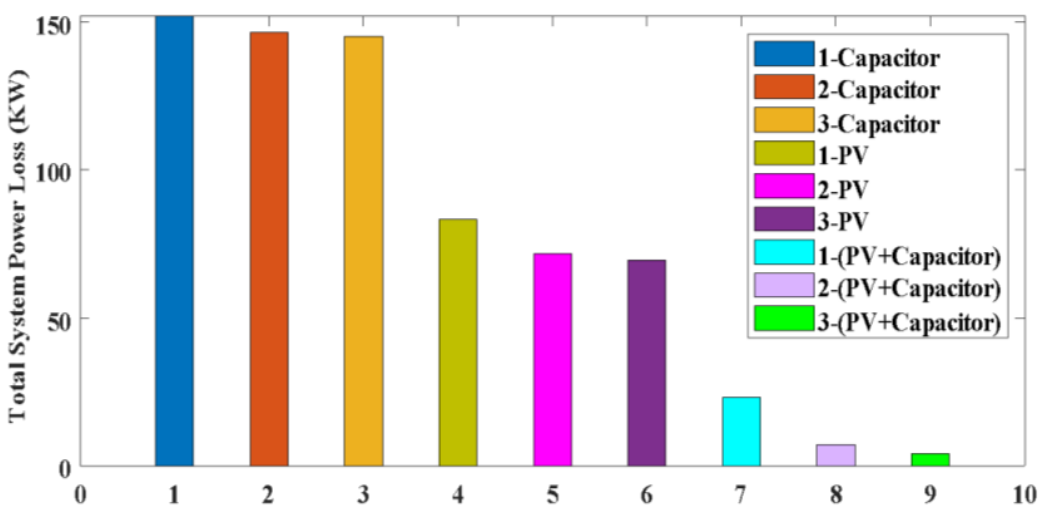

Figure 9. System losses by integrating capacitor and PV units alone or simultaneously in IEEE 69-bus RDS 
From Table 4, simultaneous allocation of PV with capacitor units in RDS gives better results than other cases. The system losses are decreased to $23.169 \mathrm{KW}, 7.201 \mathrm{KW}$ and $4.253 \mathrm{KW}$ by integrating one, two and three PV with capacitor units in RDS, respectively. From Figure 11, the optimal allocation of one and two PV with capacitor units simultaneously in RDS improves the summation of voltage stability index to 65.721 and 67.4824, respectively. installing one, two and three PV with capacitor units simultaneously in RDS improve the minimum voltage to 0.9725 pu at bus $27,0.9943$ pu at bus 50 and 0.9943 pu at bus 50 , respectively. Installing three PV with capacitor units simultaneously in RDS achieves the best results as it reduces the summation of voltage deviation to $0.0001 \mathrm{pu}$ and enhances the summation of voltage stability index to 67.7437. The summation of voltage deviation of the system is reduced to $0.0119 \mathrm{pu}$ and $0.0004 \mathrm{pu}$ by integrating one and two PV with capacitor simultaneously in RDS, respectively. From Table 5, NPO algorithm is an efficient to obtain the best results in minimizing the system losses to $152.041 \mathrm{KW}$ compared to WOA with system losses $152.064 \mathrm{KW}$ for integrating one PV alone in RDS.

Table 4. The obtained results for integrating PV alone, capacitor alone, and PV with capacitor simultaneously

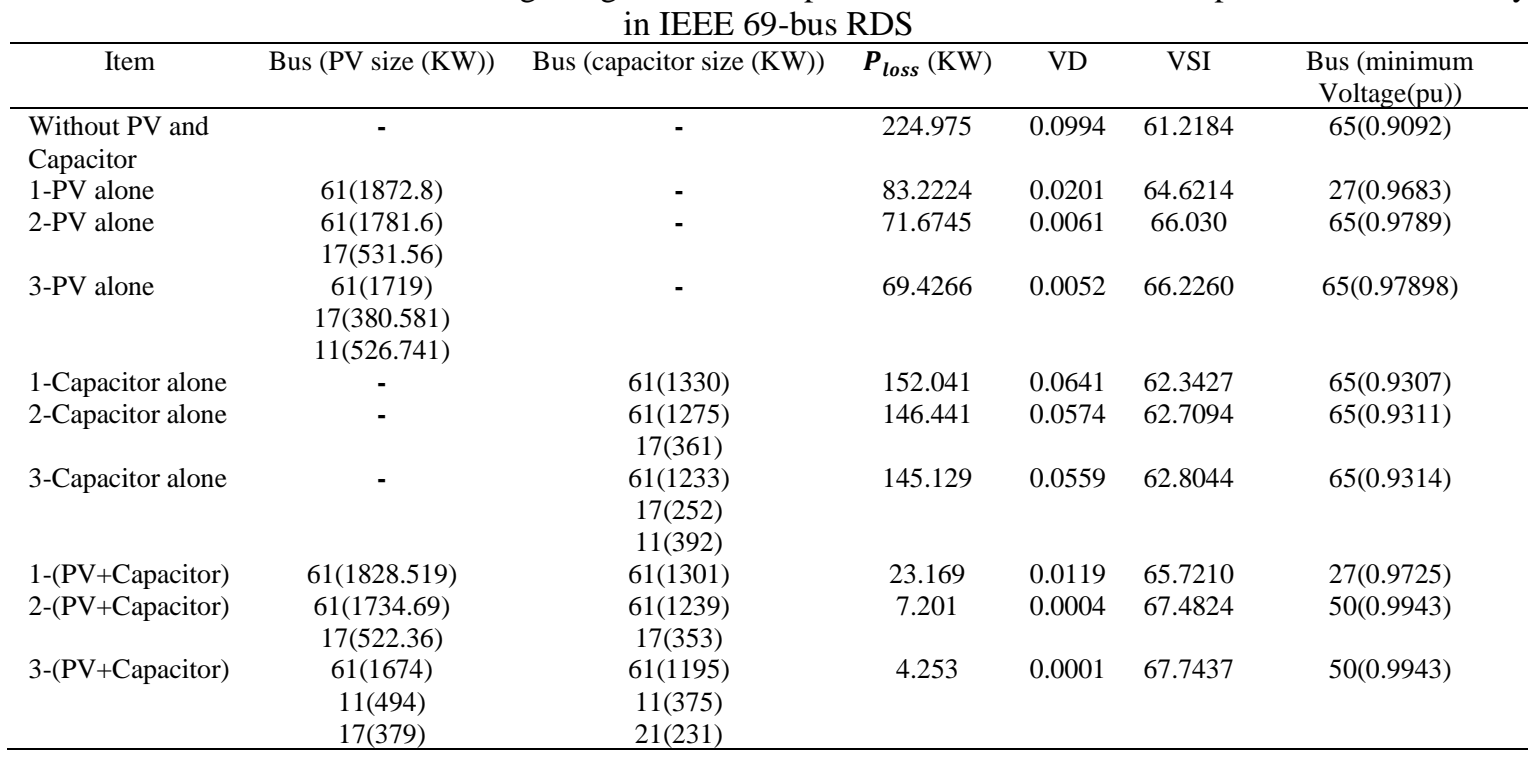

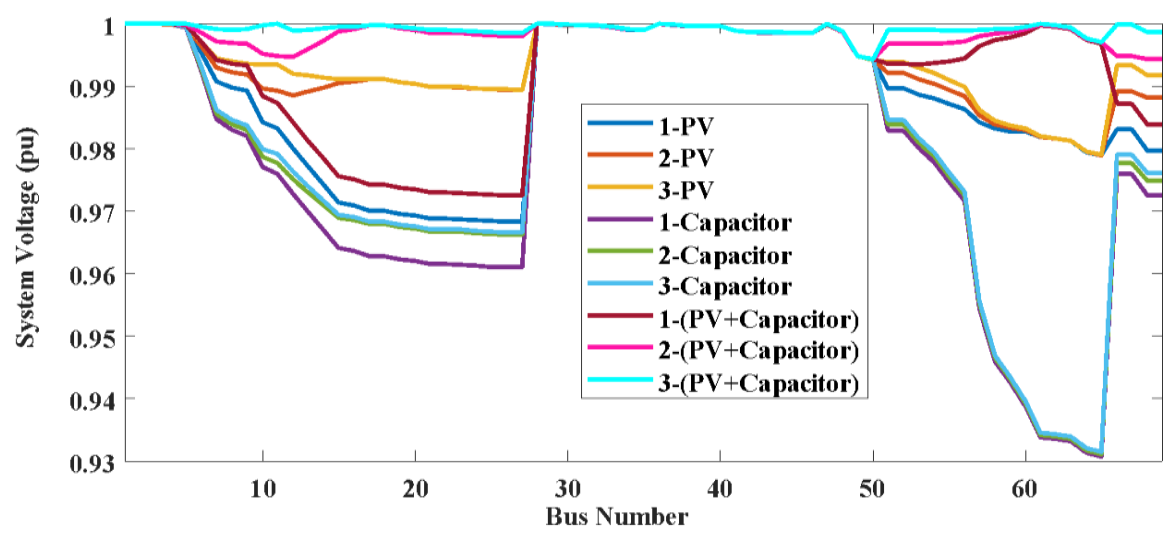

Figure 10. Bus voltages by integrating PV and capacitor units alone or simultaneously in IEEE 69-bus RDS 


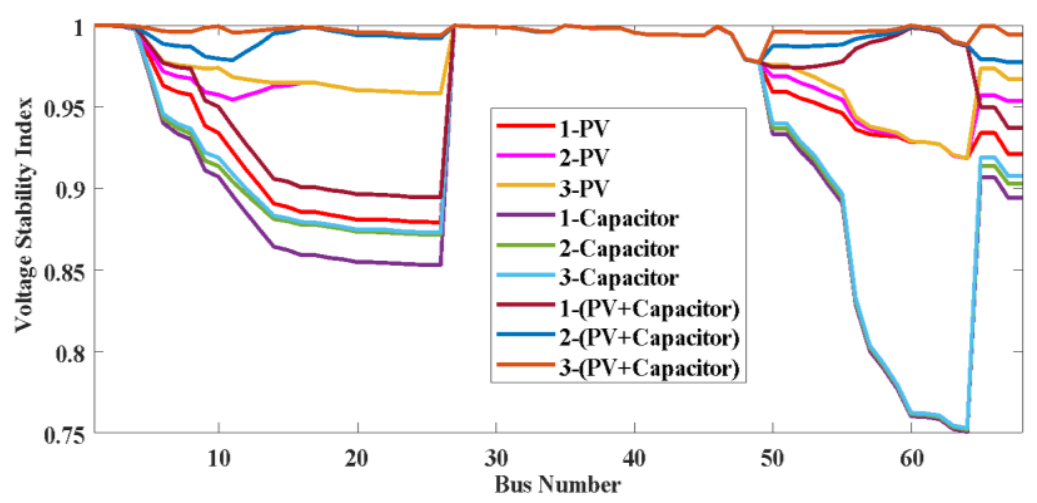

Figure 11. Voltage stability index of the system by integrating PV and capacitor units alone or simultaneously in IEEE 69-bus RDS

Table 5. The comparison results between the presented algorithm and other algorithms in IEEE 69-bus RDS

\begin{tabular}{lcccccc}
\hline \multicolumn{1}{c}{ Item } & NPO & MFO [8] & Hybrid [24] & WOA [25] & SCA [26] & PSO [27] \\
\hline 1-PV alone & 83.2224 & 83.224 & 83.372 & - & - & - \\
2-PV alone & 71.6745 & 71.679 & 71.82 & - & - & - \\
3-PV alone & 69.4266 & - & 69.52 & - & - & - \\
1-Capacitor alone & 152.041 & - & - & 152.064 & - & - \\
2-Capacitor alone & 146.441 & - & - & - & 147.762 & - \\
3-Capacitor alone & 145.129 & - & - & - & - & - \\
1-(PV+Capacitor) & 23.169 & - & - & - & - & 25.9 \\
2-(PV+Capacitor) & 7.201 & - & - & - & - & - \\
3-(PV+Capacitor) & 4.253 & - & - & - & - & - \\
\hline
\end{tabular}

\section{CONCLUSION}

This paper has proposed a new application of NPO algorithm to determine the best sizes and locations of PV and capacitor alone or simultaneously in distribution networks. RLSF has been applied to obtain the superior candidate buses by installing PV and capacitor units in distribution networks. From results, it is observed that integration of multiple PV and capacitor units obtains superior results than integration of single PV and capacitor. Also, integrating PV with capacitor simultaneously obtains superior results than integrating of capacitor and PV alone in RDS. NPO algorithm is able to obtain the best results when compared to than other recent algorithms. Therefore, the reduction in real power loss by installing three PV alone, capacitor alone and PV with capacitor in IEEE 33-bus RDS are 65.5\%, 34.2\% and 94.4\%, respectively. Also, the reduction in real power loss by installing three PV alone, capacitor alone and PV with capacitor in IEEE 69-bus RDS are 69.1\%, 35.5\% and 98.1\%, respectively. In the future work, new applications of nomadic people optimizer in solving several other complex optimization problems related to power system could be studied.

\section{REFERENCES}

[1] Z. Abdmouleh, A. Gastli, L. Ben-Brahim, M. Haouari, and N. A. Al-Emadi, "Review of optimization techniques applied for the integration of distributed generation from renewable energy sources," Renewable Energy, vol. 113, pp. 266-280, 2017, doi: 10.1016/j.renene.2017.05.087.

[2] S. Mekhilef, R. Saidur, and M. Kamalisarvestani, "Effect of dust, humidity and air velocity on efficiency of photovoltaic cells," Renewable and Sustainable Energy Reviews, vol. 16, no. 5, pp. 2920-2925, 2012, doi: 10.1016/j.rser.2012.02.012.

[3] F. Rizzi, N. J. van Eck, and M. Frey, "The production of scientific knowledge on renewable energies: Worldwide trends, dynamics and challenges and implications for management," Renewable Energy, vol. 62, pp. 657-671, 2014, doi: 10.1016/j.renene.2013.08.030.

[4] J. Paska, P. Biczel, and M. Kłos, "Hybrid power systems-An effective way of utilising primary energy sources," Renewable Energy, vol. 34, no. 11, pp. 2414-2421, 2009, doi: 10.1016/j.renene.2009.02.018.

[5] A. Raheem, et al., "Renewable energy deployment to combat energy crisis in Pakistan," Energy, Sustainability and Society, vol. 6, no. 1, pp. 1-13, 2016, doi: 10.1186/s13705-016-0082-z.

[6] A. Ashfaq and A. Ianakiev, "Features of fully integrated renewable energy atlas for Pakistan; wind, solar and cooling," Renewable and Sustainable Energy Reviews, vol. 97, pp. 14-27, 2018, doi: 10.1016/j.rser.2018.08.011. 
[7] N. A. Ludin, et al., "Prospects of life cycle assessment of renewable energy from solar photovoltaic technologies: a review," Renewable and Sustainable Energy Reviews, vol. 96, pp. 11-28, 2018, doi: 10.1016/j.rser.2018.07.048.

[8] H. Abdel-Mawgoud, S. Kamel, M. Ebeed, and M. M. Aly, "An efficient hybrid approach for optimal allocation of DG in radial distribution networks," 2018 International Conference on Innovative Trends in Computer Engineering (ITCE), 2018, pp. 311-316, doi: 10.1109/ITCE.2018.8316643.

[9] H. Abdel-Mawgoud, S. Kamel, M. Ebeed, and A. Youssef, "Optimal allocation of renewable dg sources in distribution networks considering load growth," 2017 Nineteenth International Middle East Power Systems Conference (MEPCON), 2017, pp. 1236-1241, doi: 10.1109/MEPCON.2017.8301340.

[10] S. Q. Salih and A. A. Alsewari, "A new algorithm for normal and large-scale optimization problems: Nomadic People Optimizer," Neural Computing and Applications, vol. 32, no. 14, pp. 10359-10386, 2020, doi: 10.1007/s00521-019-04575-1.

[11] M. Milovanović, J. Radosavljević, and B. Perovic, "Optimal location and sizing of capacitor banks in distribution networks to reduce harmonic distortion and improve voltage profile using genetic algorithm," Tehnika, vol. 72, no. 6, pp. 867-875, 2017, doi: 10.5937/tehnika1706867M.

[12] G. G. Soma, "Optimal Sizing and Placement of Capacitor Banks in Distribution Networks Using a Genetic Algorithm," Electricity, vol. 2, no. 2, pp. 187-204, 2021, doi: 10.3390/electricity2020012.

[13] M. A. Tolba, A. A. Z. Diab, V. N. Tulsky, and A. Y. Abdelaziz, "LVCI approach for optimal allocation of distributed generations and capacitor banks in distribution grids based on moth-flame optimization algorithm," Electrical Engineering, vol. 100, no. 3, pp. 2059-2084, 2018, doi: 10.1007/s00202-018-0684-x.

[14] P. D. P. Reddy, V. C. V. Reddy, and T. G. Manohar, "Whale optimization algorithm for optimal sizing of renewable resources for loss reduction in distribution systems," Renewables: Wind, Water, and Solar, vol. 4, no. 3, 2017, doi: 10.1186/s40807-017-0040-1.

[15] A. El-Fergany, "Optimal allocation of multi-type distributed generators using backtracking search optimization algorithm," International Journal of Electrical Power \& Energy Systems, vol. 64, pp. 1197-1205, 2015, doi: 10.1016/j.ijepes.2014.09.020.

[16] S. K. Injeti, S. M. Shareef, and T. V. Kumar, "Optimal Allocation of DGs and Capacitor Banks in Radial Distribution Systems," Distributed Generation \& Alternative Energy Journal, vol. 33, no. 3, pp. 6-34, 2018, doi: 10.1080/21563306.2018.12016723.

[17] E. Karunarathne, J. Pasupuleti, J. Ekanayake, and D. Almeida, "Optimal Placement and Sizing of DGs in Distribution Networks Using MLPSO Algorithm," Energies, vol. 13, no. 23, pp. 6185, 2020, doi:10.3390/en13236185.

[18] Y. Thangaraj and R. Kuppan, "Multi-objective simultaneous placement of DG and DSTATCOM using novel lightning search algorithm," Journal of Applied Research and Technology, vol. 15, no. 5, pp. 477-491, 2017, doi: 10.1016/j.jart.2017.05.008.

[19] A. Abdelaziz, E. Ali, and S. A. Elazim, "Flower pollination algorithm and loss sensitivity factors for optimal sizing and placement of capacitors in radial distribution systems," International Journal of Electrical Power \& Energy Systems, vol. 78, pp. 207-214, 2016, doi: 10.1016/j.ijepes.2015.11.059.

[20] U. Eminoglu and M. H. Hocaoglu, "Distribution systems forward/backward sweep-based power flow algorithms: a review and comparison study," Electric Power Components and Systems, vol. 37, no. 1, pp. 91-110, 2008, doi: $10.1080 / 15325000802322046$

[21] E. Ali, S. Abd Elazim, and A. Abdelaziz, "Ant lion optimization algorithm for renewable distributed generations," Energy, vol. 116, pp. 445-458, 2016, doi: 10.1016/j.energy.2016.09.104.

[22] J. S. Savier and D. Das, "Impact of Network Reconfiguration on Loss Allocation of Radial Distribution Systems," in IEEE Transactions on Power Delivery, vol. 22, no. 4, pp. 2473-2480, Oct. 2007, doi: 10.1109/TPWRD.2007.905370.

[23] B. Venkatesh and R. Ranjan, "Optimal radial distribution system reconfiguration using fuzzy adaptation of evolutionary programming," International Journal of Electrical Power \& Energy Systems, vol. 25, no. 10, pp. 775-780, 2003, doi: 10.1016/S0142-0615(03)00046-2.

[24] S. Kansal, V. Kumar, and B. Tyagi, "Hybrid approach for optimal placement of multiple DGs of multiple types in distribution networks," International Journal of Electrical Power \& Energy Systems, vol. 75, pp. 226-235, 2016, doi: 10.1016/j.ijepes.2015.09.002.

[25] P. D. P. Reddy, V. C. V. Reddy, and T. G. Manohara, "Optimal renewable resources placement in distribution networks by combined power loss index and whale optimization algorithms," Electrical Power \& Energy Systems, vol. 5, no. 2, pp. 175-191, 2018, doi: 10.1016/j.jesit.2017.05.006.

[26] S. R. Biswal and G. Shankar, "Optimal Sizing and Allocation of Capacitors in Radial Distribution System using Sine Cosine Algorithm," 2018 IEEE International Conference on Power Electronics, Drives and Energy Systems (PEDES), 2018, pp. 1-4, doi: 10.1109/PEDES.2018.8707739.

[27] M. Aman, G. Jasmon, K. Solangi, A. Bakar, and H. Mokhlis, "Optimum simultaneous DG and capacitor placement on the basis of minimization of power losses," International Journal of Computer and Electrical Engineering, vol. 5, no. 5, pp. 516-522, 2013, doi: 10.7763/IJCEE.2013.V5.764. 


\section{BIOGRAPHIES OF AUTHORS}
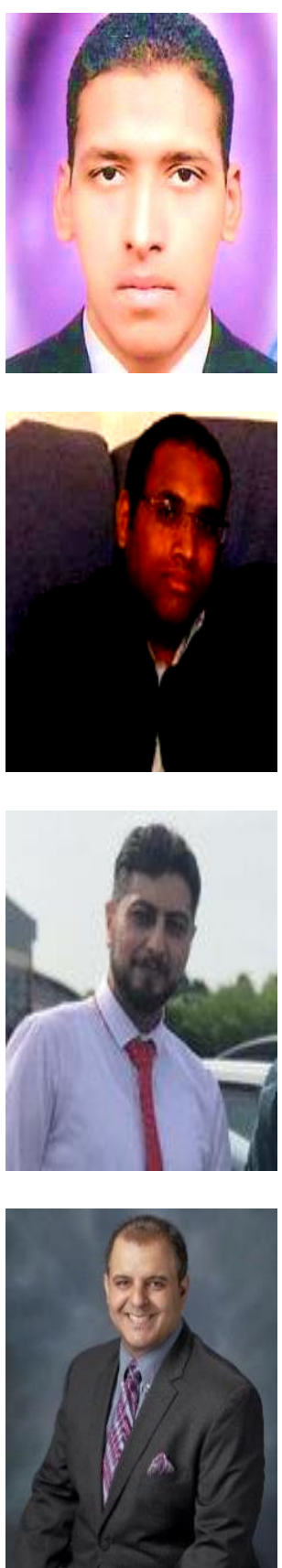

Hussein Abdel Mawgoud received his B.Sc. and M.Sc degrees from Aswan University, Egypt in 2014 and 2019, respectively. He is currently pursuing his Ph.D degree in Department of Electrical Engineering, Aswan Faculty of Engineering, Aswan University. His research activities include renewable energy and power system optimization.

Salah Kamel received the international Ph.D. degree from University of Jaen, Spain (Main) and Aalborg University, Denmark (Host) in Jan. 2014. He is an Associate Professor in Electrical Engineering Department, Aswan University. Also, He is a Leader for power systems research group in the Advanced Power Systems Research Laboratory (APSR Lab), Aswan, Egypt. His research activities include power system analysis and optimization, smart grid and renewable energy systems.

Sinan Q. Salih received the M.Sc. degree in computer sciences from Universiti Tenaga Nasional (UNITEN), in 2012, and the Ph.D. degree from Universiti Malaysia Pahang (UMP), Malaysia, in 2018. He is major in machine learning, optimization, and data analytic. His current research interests include optimization algorithms, nature-inspired metaheuristics, machine learning, and feature selection for real-world problems.

Ali S. Alghamdi received his dual B.S. degree (with high honor) in computer and electrical engineering from Lawrence Technological University, Southfield, Michigan, USA, in 2010 and 2012 respectively, and MSc in Electrical and Computer engineering from Lawrence Technological University, Southfield, Michigan, USA, in 2012. Also, he received his Ph.D. in electrical and computer engineering from Oakland University, Rochester, Michigan, USA, in 2017. He is currently an assistant professor and acting chair of the department of electrical engineering at the college of engineering at Majmaah University, Saudi Arabia. His current research interests include statistical digital signal processing, communication systems, adaptive filter, modern control in power system, optoelectronics Nano-materials in renewable energy, and wireless sensor network innovation. 